\title{
É POSSÍVEL VER IMAGENS? (OU DO PORQUÊ VAN FRAASSEN DEVERIA REVER A SUA ABORDAGEM EM RELAÇÃO A ELAS) ${ }^{1}$
}

\author{
Alessio Gava ${ }^{2}$ \\ Universidade Estadual do Paraná (UNESPAR) \\ (i) http://orcid.org/0000-0002-0426-8392 \\ E-mail: alessiogava@yahoo.it
}

\section{RESUMO:}

Em seu último livro (2008), Bas van Fraassen, o fundador do empirismo construtivo, propôs uma categorização das imagens em forma de tabela. $\mathrm{O}$ intuito dele, todavia, era discutir da realidade daquilo que essas representam e não enfrentar a questão das imagens em si. Uma das consequências é que permaneceu em aberto saber o que seriam, então, aquelas imagens que o filósofo holandês chama de alucinações públicas - reflexos na água, miragens no deserto, arco-íris, etc. Neste artigo será defendido que somente deveriam ser consideradas como imagens aquelas que o são no sentido relevante (representacional) e que, por essa e outras razões, a tabela de van Fraassen deveria ser corrigida. Ademais, como a física nos ensina, a classe das imagens que têm esse nome, mas que na verdade são objetos, é mais ampla do que van Fraassen pensa(va). O conjunto dos objetos que podem ser observados não contém somente coisas concretas, mas vai além daquilo que o 'realismo do senso comum' sugere. Além de pedras, oceanos, bicicletas, podemos ver também arco-íris, reflexos na água e fenômenos similares.

PALAVRAS-CHAVE: Alucinações públicas; Empirismo construtivo; Imagens; Observação; Van Fraassen.

\section{CAN WE SEE IMAGES? (OR WHY VAN FRAASSEN SHOULD RECONSIDER HIS APPROACH TOWARDS THEM)}

\begin{abstract}
:
In his last book (2008), Bas van Fraassen, the originator of constructive empiricism, put forward a table containing a categorization of images. His aim, however, was to discuss the reality of what they represent and not addressing the issue of images per se. One of the consequences is that it remained an open question what 'public hallucinations' - reflections in the water, rainbows and the like - are. In this paper it will be defended that only images in the relevant (representational) sense should be considered as such. For this and other reasons, van Fraassen's diagram should be amended. Moreover, as Physics teaches us, the class of the so-called 'images' that are actually objects is wider than van Fraassen reckons. The set of the observable objects do not contain only concrete things, but goes beyond what 'common sense realism' suggests. In addition to rocks, oceans and bycycles, we can also see rainbows, reflections in the water and the like.
\end{abstract}

KEYWORDS: Constructive empiricism; Images; Observation; Public hallucinations; Van Fraassen.

\footnotetext{
${ }^{1} \mathrm{O}$ presente trabalho beneficiou-se de conversas esclarecedoras com o Prof. Otávio Bueno, da University of Miami (EUA), ao qual registro meu agradecimento.

2 Doutor em Lógica e Filosofia da Ciência pela Universidade Federal de Minas Gerais (UFMG), Belo Horizonte - MG, Brasil. Professor da Universidade Estadual do Paraná (UNESPAR), Apucarana - PR, Brasil.
}

GAVA, Alessio. É possível ver imagens? (Ou do porquê van Fraassen deveria rever a sua abordagem em relação a elas). Griot : Revista de Filosofia, Amargosa-BA, v.18, n.2, p.143-160, dezembro, 2018. 


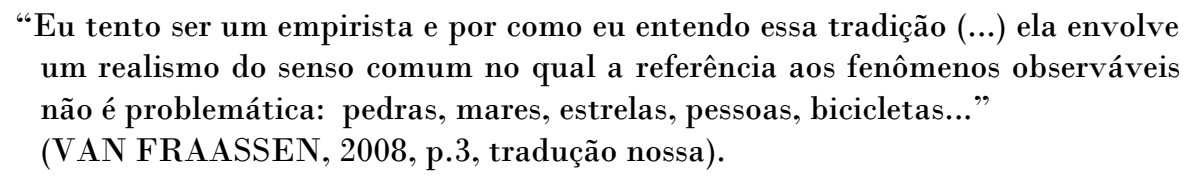

Quase quatro décadas atrás, em seu seminal livro $A$ Imagem Científica (1980), o filósofo holandês Bas van Fraassen propôs uma nova visão acerca da ciência e de seus objetivos, que batizou de 'empirismo construtivo', segundo a qual o intuito da atividade científica é dar-nos teorias que sejam empiricamente adequadas (cf. VAN FRAASSEN [1980] 2007, p.33-34).

Segundo van Fraassen, uma teoria científica é um conjunto de modelos matemáticos e certas partes desses modelos (as subestruturas empíricas) são candidatos à representação direta dos fenômenos observáveis. "As estruturas que podem ser descritas em relatos experimentais e de medição podemos chamar de aparências; a teoria é empiricamente adequada se possui algum modelo tal que todas as aparências sejam isomórficas a subestruturas empíricas daquele modelo" (VAN FRAASSEN 2007, p.122). Dito de modo informal, uma teoria é empiricamente adequada se ela "salva os fenômenos', no sentido das partes observáveis do mundo, conforme o antigo ditado (cf. VAN FRAASSEN 2007, p.22 e 2008, 286); ou seja, se é verdadeiro o que ela diz sobre as coisas observáveis e eventos no mundo (cf. VAN FRAASSEN 2007, 34).

Fica assim evidente que essa vertente filosófica antirrealista depende de modo crucial da dicotomia observável/inobservável. Ora, em A Imagem Científica, van Fraassen afirmou peremptoriamente que uma observação é "um ato de percepção sem ajuda" (VAN FRAASSEN 2007, p.38). Com isso, ficariam excluídos da categoria dos observáveis os paramécios e todas as outras entidades que não podem ser vistas a olho nu, mas que comumente são detectadas por meio de microscópios.

Para defender essa polêmica posição, van Fraassen negou que aparelhos como o microscópio nos permitam 'ver' entidades às quais não temos acesso direto. Ele considera, diversamente, que os instrumentos óticos são 'geradores de imagens'. No caso dos microscópios, ademais, o filósofo holandês considera legítimo suspender o juízo acerca da veracidade das imagens que esses aparelhos produzem, pois não haveria como comprová-la empiricamente. Em dois trabalhos publicados neste novo milénio, van Fraassen foi além e discutiu de imagens em geral, chegando a propor uma categorização das mesmas. $O$ intuito, porém, era apenas argumentar a favor da sua visão acerca dos microscópios, para tentar legitimar a manutenção de uma posição agnóstica acerca daquilo que as imagens microscópicas deveriam representar. Por isso a discussão de van Fraassen acerca das imagens limita-se a pouquíssimas páginas e não tem a pretensão de constituir um 'tratado' sobre o tema - nem mesmo de forma muito sucinta e superficial.

O objetivo deste trabalho é mostrar que, perante o exposto, até mesmo para van Fraassen o sentido relevante de 'imagem' é aquele representacional e que, por essa razão, a categorização mencionada acima deveria ser revista. A categoria das imagens que têm esse nome, pois, mas que na verdade são objetos, é mais ampla do que van Fraassen pensa(va) e inclui todas aquelas que em física são chamadas de imagens (tanto reais quanto virtuais). Assim sendo, a classe dos objetos que podem ser observados não

GAVA, Alessio. É possível ver imagens? (Ou do porquê van Fraassen deveria rever a sua abordagem em relação a elas). Griot : Revista de Filosofia, Amargosa-BA, v.18, n.2, p.143-160, dezembro, 2018. 
contém apenas coisas concretas, mas vai além daquilo que o 'realismo do senso comum' sugere.

\section{A questão das imagens e a tabela de van Fraassen}

No início deste século, no artigo "Constructive Empiricism now", van Fraassen foi categórico em relação à possibilidade de observarmos imagens. Escreveu: "Nós nunca vemos imagens, pois as imagens não existem" (VAN FRAASSEN 2001, p.158, tradução nossa), para, na página seguinte, explicar que quando alguém afirma que viu uma imagem, isso nada mais é do que um juízo espontâneo em resposta a uma experiência. Mas, se depreende, esse não é um uso correto do verbo ver, a não ser quando aquilo que chamamos de imagem corresponde a um objeto real, como quando olhamos para uma pintura ou para uma foto. Em todos os outros casos, tanto no que diz respeito a 'imagens puramente subjetivas', como pós-imagens e alucinações 'privadas', quanto em relação àquelas que ele chama de 'alucinações públicas', não se trata de coisas e nem, já que não existem, de entidades (objetos, eventos, processos), portanto não podem ser vistas.

Essa classificação de imagens foi organizada por van Fraassen em um 'catálogo' e proposta dez anos atrás em seu último livro, Scientific Representation, na forma da tabela seguinte (VAN FRAASSEN 2008, p.104, tradução nossa, ênfases no original):

\section{Tabela 1}

As categorias das imagens

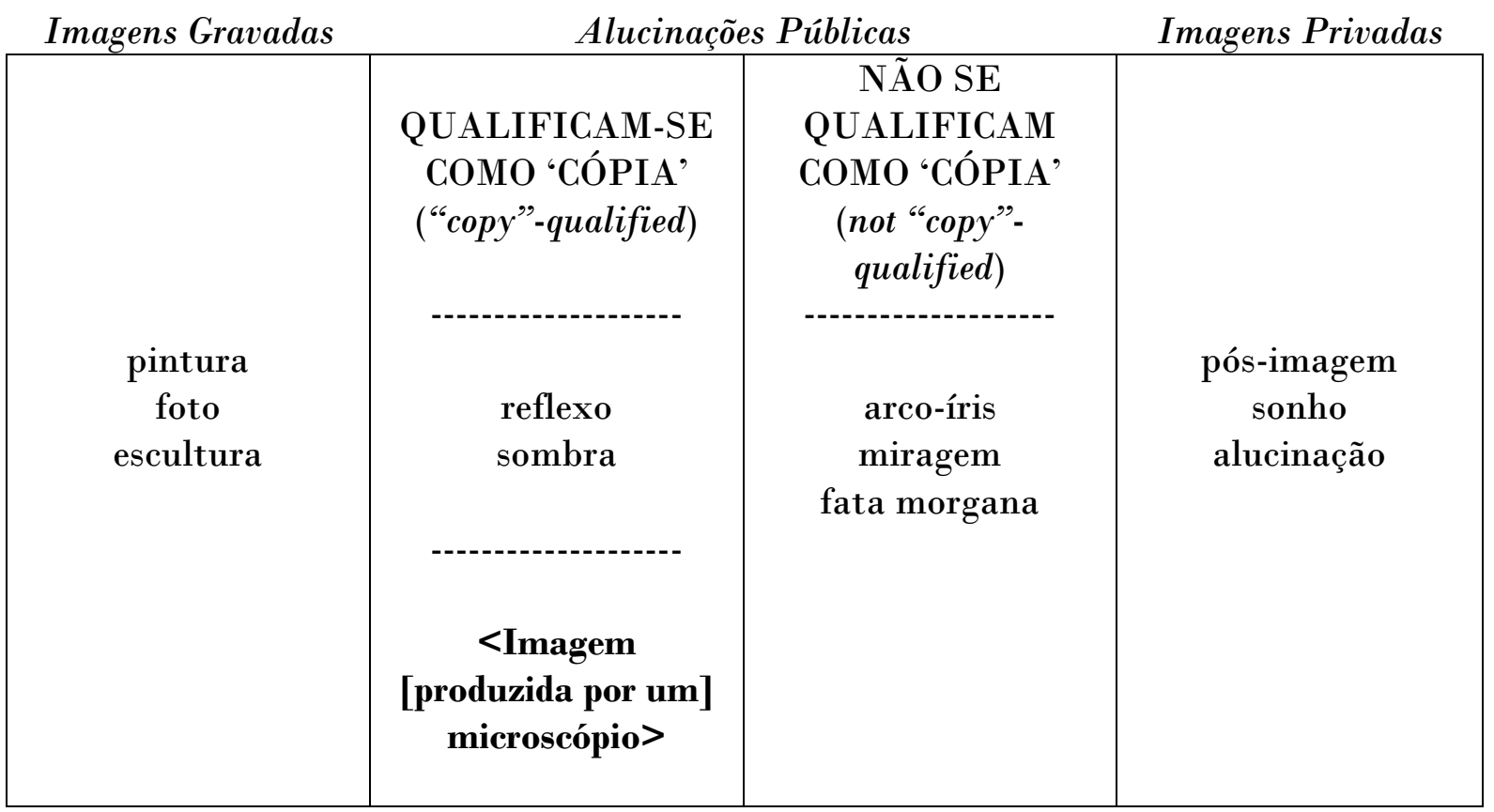

GAVA, Alessio. É possível ver imagens? (Ou do porquê van Fraassen deveria rever a sua abordagem em relação a elas). Griot : Revista de Filosofia, Amargosa-BA, v.18, n.2, p.143-160, dezembro, 2018. 
Na primeira coluna à esquerda, é explicado, encontram-se as imagens que são de fato coisas, como fotografias e pinturas. Já nas outras colunas encontram-se todas aquelas imagens que não são coisas, segundo a categorização já proposta no artigo de 2001. Tanto no artigo quanto no livro, porém, van Fraassen não aprofunda a questão das imagens em si, e o discurso passa a ser sobre a realidade daquilo que elas representam - já que o objetivo é explicar porque seria correto, ou pelo menos não irracional, manter-se agnóstico em relação à realidade das entidades detectadas por meio de um microscópio.

Dessa maneira, permanece em aberto a questão de saber o que seriam, então, aquelas imagens que ele chama de alucinações públicas - reflexos na água, miragens no deserto, arco-íris, etc. Em Scientific Representation, pois, reafirma-se que essas não são coisas, mas a existência delas não é mais negada, diferentemente do que aconteceu em 2001. No quarto capítulo, com efeito, se lê: “Quando você vê o reflexo de uma árvore na água, você não está vendo uma coisa; não é o caso que um reflexo seja nada (a reflection is not nothing), ele é algo, mas não é uma coisa, não é um objeto material" (VAN FRAASSEN 2008, p.105, tradução nossa).

Ora, admitir que as 'alucinações públicas' não constituem uma categoria à parte e são, diversamente, entidades - interpretando o termo como significando, segundo o uso do van Fraassen, uma entre as três subclasses de objetos, eventos ou processos permitiria resolver vários problemas e evitar o surgimento de outros, como aquele de uma inflação ontológica que ninguém esperaria de um empirista declarado como o filósofo holandês (cf. GAVA 2016) - mesmo que, em público, ele sempre afirme modestamente que apenas 'tenta ser' um empirista.

De qualquer modo, a tabela de van Fraassen trata de sistematizar algo que é experienciado continuamente por qualquer ser humano, mas a palavra imagem é tão genérica que debaixo da asa dela encontra abrigo praticamente tudo aquilo que envolve a visão humana de maneira a representar algo, até no sentido amplo de ser a forma ou o aspecto daquilo que é visto. E não somente, como testemunha o fato de o livro no qual o empirismo construtivo viu a luz ter o título de $A$ Imagem Científica, locução que não faz nenhuma referência ao fato de ver ou representar visualmente algo. É um pouco aquilo que acontece, em Minas Gerais, com o uso da palavra trem, que pode ser aplicada praticamente a qualquer coisa ou estado de coisas, se bem que, no caso da palavra imagem, isso se dá em escala menor e de maneira mais circunscrita.

Por isso, incluir o arco-íris entre as imagens pode até ser legítimo, mas querendo delimitar o uso da palavra de maneira a considerar seu papel representacional, ${ }^{3}$ somente envolvendo o sentido da visão, tal escolha parece discutível. Uma imagem deve ser

\footnotetext{
${ }^{3}$ Como foi dito anteriormente, o objetivo de van Fraassen, ao discutir de imagens, é explicar porque seria correto, ou pelo menos não irracional, manter-se agnóstico em relação à realidade das entidades detectadas por meio de um microscópio. Tal aparelho, porém, segundo o filósofo holandês, é um 'gerador de imagens' e não, diferentemente daquilo que muitos pensam, uma 'janela para o inobservável' (cf. VAN FRAASSEN 2001, p.154-155 e 2008, p.100). Assim sendo, a questão deixa de ser se é possível 'ver' por meio de um microscópio e se torna aquela de saber se as imagens que esse produz representam algo real ou se, em alternativa, é legítimo suspender o juízo acerca desse fato. Contudo, fica claro que então, até mesmo para van Fraassen, o sentido de 'imagem' que interessa é aquele representacional.
}

GAVA, Alessio. É possível ver imagens? (Ou do porquê van Fraassen deveria rever a sua abordagem em relação a elas). Griot : Revista de Filosofia, Amargosa-BA, v.18, n.2, p.143-160, dezembro, 2018. 
imagem de algo, senão na tabela poderíamos incluir também nuvens com forma de cachorro ou a península italiana, por ela relembrar uma bota. Essas, aliás, teriam mais direito de ser consideradas imagens de algo do que um arco-íris, que não se sabe do que deveria ser uma imagem, já que não se parece com nada. ${ }^{4}$ Os outros dois 'fenômenos' classificados por van Fraassen como alucinações públicas not "copy"-qualified, ademais, parecem estar na coluna errada. Se fala em miragem e fata morgana, com efeito, quando um objeto é visto deformado ou deslocado por causa da refração da luz solar na atmosfera terrestre (vejam-se as figuras a seguir), portanto aquelas que se produzem nessas situações são imagens "copy"-qualified, ${ }^{5}$ contrariamente à catalogação proposta em Scientific Representation.

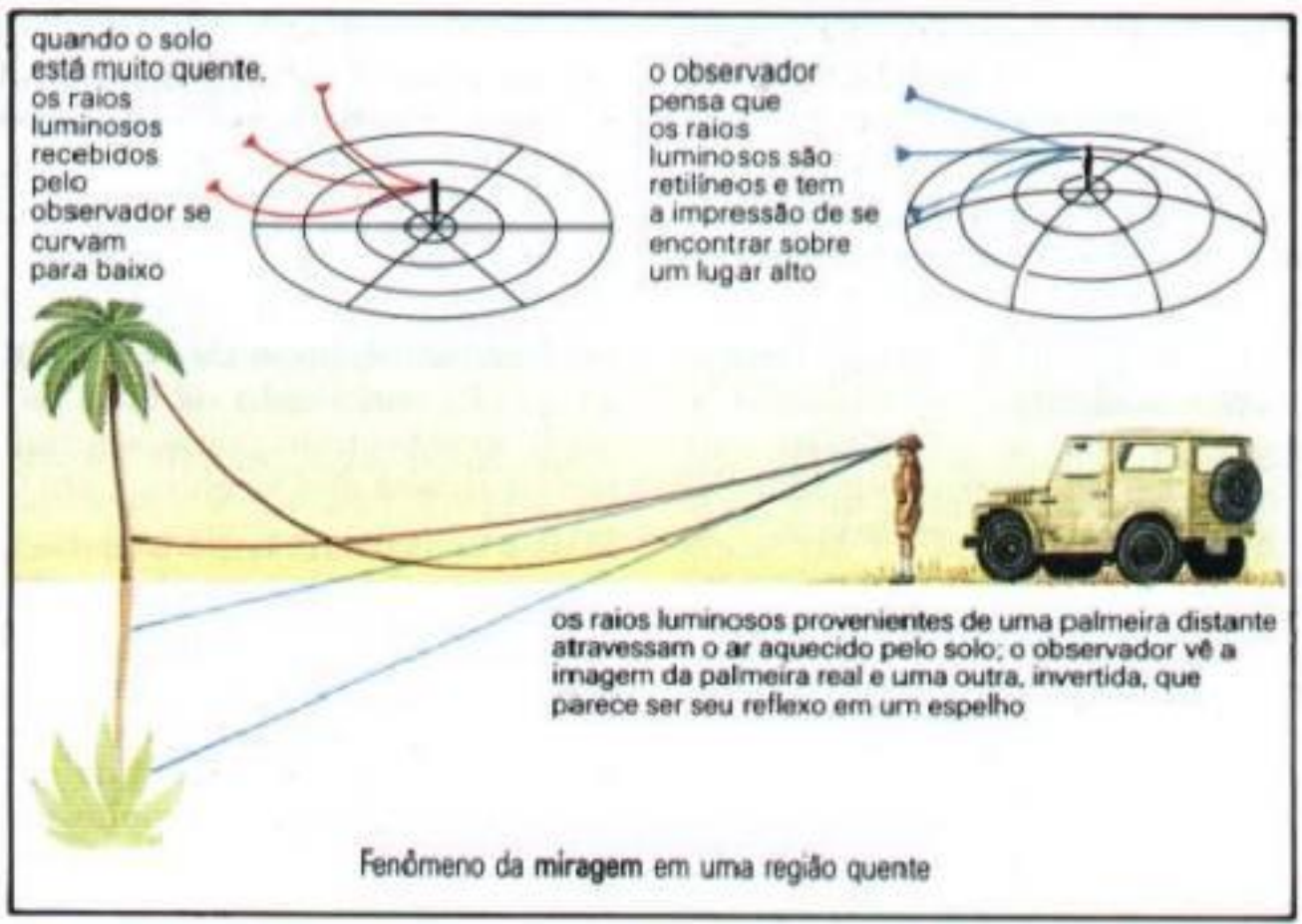

Figura 1 - Fenômeno da miragem em uma região quente

Fonte <http://megaarquivo.com/tag/miragem>, último acesso em 02/04/2014

\begin{abstract}
${ }^{4}$ Se parece com um arco, evidentemente, conforme o próprio nome do 'fenômeno' sugere, todavia não reproduz (e nem se parece com) nenhum arco material conhecido, do qual poder ser considerado uma cópia ou uma imitação (como também diz van Fraassen). Considerá-lo um tipo de imagem, portanto, nos parece questionável.

${ }^{5}$ Um célebre relato histórico de uma fata morgana encontra-se em "Account of a Singular Instance of Atmospherical Refraction" (1798), no qual William Latham conta como um dia, no verão de 1797, muitas pessoas congregaram-se na praia de Hastings (Inglaterra), para observar o litoral francês. Esse, distante na verdade 40-50 milhas, parecia muito mais próximo, a ponto de os pescadores conseguirem dizer o nome de cada rocha vista (cf. LATHAM 1798). Esse fenômeno repetiu-se em 1987, segundo dizem, enquanto acontece com uma certa frequência do lado francês do Canal da Mancha. O mesmo fenômeno é bastante comum no Estreito de Messina, que separa a Sicília da Calábria, no sul da Itália.
\end{abstract}

GAVA, Alessio. É possível ver imagens? (Ou do porquê van Fraassen deveria rever a sua abordagem em relação a elas). Griot : Revista de Filosofia, Amargosa - BA, v.18, n.2, p.143-160, dezembro, 2018. 


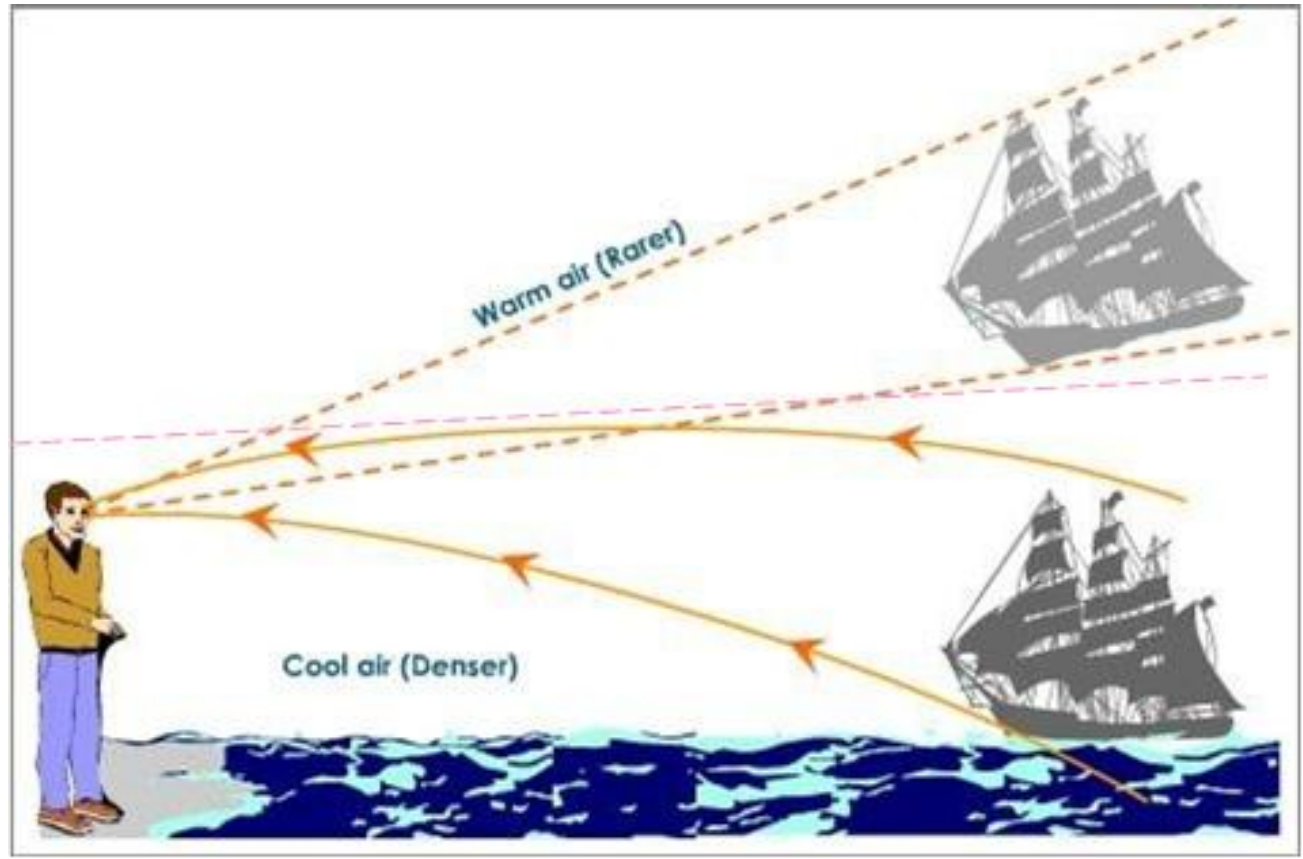

Figura 2 - Fenômeno da fata morgana em uma região fria

Fonte <http://ajpadilla.wordpress.com/2012/12/21/fata-morgana $>$, último acesso em 02/04/2014

Aliás, não deveria nem existir uma coluna de imagens 'que não são cópia de nada', porque essas não se qualificam como imagens no sentido relevante. Senão, qualquer outra coisa ('feita de luz'?), além do arco-íris, poderia ser abrigada nela. A última coluna, das 'imagens privadas', também deveria ser desconsiderada, dado o contexto no qual geralmente fala-se de observação, a saber, quando aquilo que é experienciado é objetivamente e publicamente acessível. ${ }^{6}$

Restariam, assim, duas colunas na tabela de van Fraassen (cf. tabela 2 a seguir). A primeira seria aquela das imagens gravadas, que certamente contém objetos materiais, como as famosas gravuras com as quais Gustave Doré ilustrou a Divina Comédia no final do século XIX. A segunda conteria as alucinações públicas, que seriam, todas elas, imagens de algo - como também são aquelas da primeira coluna, pelo próprio fato de elas serem imagens.

\footnotetext{
${ }^{6}$ Conforme foi explicado no início do presente trabalho, a adequação empírica consistiria em um isomorfismo entre a parte observacional de um modelo de uma teoria e um modelo de dados construído a partir das aparências (cf. VAN FRAASSEN 2008, p.168 e 238 e GIERE 2009, p.107-108). Ora, van Fraassen não é um sensualista, como Locke ou Berkeley, e em A Imagem Científica negou a existência dos dados sensoriais de modo encarecido. Por isso, "aquelas que ele chama de aparências são públicas", como escreveu Ronald Giere em uma recente resenha de Scientific Representation (GIERE 2009, p.107, tradução nossa).
}

GAVA, Alessio. É possível ver imagens? (Ou do porquê van Fraassen deveria rever a sua abordagem em relação a elas). Griot : Revista de Filosofia, Amargosa-BA, v.18, n.2, p.143-160, dezembro, 2018. 
Tabela 2

Categorização ontológica das imagens

\begin{tabular}{|c|c|}
\hline Imagens Gravadas & Alucinações Públicas \\
\hline $\begin{array}{l}\text { pintura } \\
\text { foto } \\
\text { escultura }\end{array}$ & 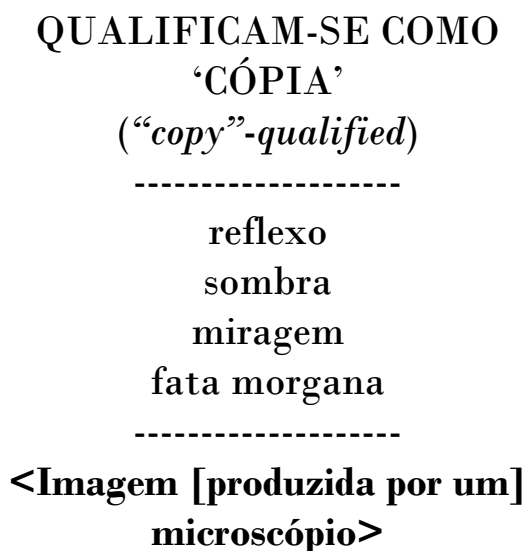 \\
\hline
\end{tabular}

A categorização responderia dessa maneira a um critério ontológico: na primeira coluna estariam incluídos objetos materiais, na segunda coluna esses fenômenos que, porém, segundo van Fraassen, não são objetos (mas que existem). Dizer que são entidades resolveria a questão da observação dos mesmos, como foi dito, mas será que isso é possível e, principalmente, legítimo? Apelar para a etimologia da palavra entidade e dizer que, se van Fraassen admite que existem, então admite do mesmo modo que se trata de entidades, não parece uma boa estratégia. Ele parece identificar entidades com coisas, no sentido material do termo, segundo uma leitura de seus textos que não parece ilegítima, e o reflexo de uma árvore na água, por exemplo, não é uma 'coisa' desse tipo. Quanto a isso é difícil não concordar com ele.

Contudo, quando se fala de imagens em ótica geométrica, objetos como aqueles da primeira coluna também são desconsiderados. A célebre estátua do David, que se encontra em Florença, apesar de ter sido realizada por Michelangelo para representar o famoso herói bíblico, é antes de tudo um (enorme) objeto de mármore. Se perguntássemos a um turista ignaro o que foi que acabou de fotografar, a resposta provavelmente seria: "Uma estátua!". O percurso dos chamados raios visuais não sofreu nenhuma interferência - ou seja, aqueles coletados pelo cristalino foram os raios diretamente emitidos (refletidos) pelo objeto - e o que foi visto foi o objeto-estátua. Dizer que foi vista uma imagem de David pode até ser legítimo, atendo-se ao sentido representacional da palavra, mas não é nessa acepção que se fala de imagens em ótica geométrica. A tabela anterior (tabela 2) deveria portanto ser modificada eliminando a primeira coluna, conforme esta a seguir (tabela 3 ):

GAVA, Alessio. É possível ver imagens? (Ou do porquê van Fraassen deveria rever a sua abordagem em relação a elas). Griot : Revista de Filosofia, Amargosa - BA, v.18, n.2, p.143-160, dezembro, 2018. 


\section{Tabela 3}

Como classificar as imagens

Imagens

\begin{tabular}{|c|} 
reflexo \\
sombra \\
miragem \\
fata morgana \\
<Imagem [produzida por um] microscópio $>$
\end{tabular}

\section{As imagens reais}

Delimitando o contexto discursivo à física, ou à ciência em geral, deveríamos distinguir entre ver um objeto, que acontece quando nossos olhos captam os raios que provêm diretamente dele, e ver uma imagem, que se dá quando coletamos os raios não diretamente, mas depois de eles terem sofrido algum tipo de interferência por parte de um outro objeto (ou mais de um), que não os tenha(m) (completamente) absorvido, mas que tenha(m) desviado o caminho retilíneo que, em circunstâncias normais, eles teriam percorrido. Mais precisamente, costuma-se falar em ver uma imagem quando entre o objeto representado e o observador intervém um sistema ótico, que interage com a luz que provém do objeto, modificando a trajetória de seus raios - quando, diversamente, vemos a Torre Eiffel da janela do avião, por exemplo, não é correto dizer que estamos vendo uma imagem (pelo menos não pelo fato de a luz que provém do famoso monumento ter interagido com o "vidro' da janela antes de chegar aos nossos olhos).

Os exemplos mais comuns de sistemas óticos, muito estudados nas aulas de física no segundo grau, são as lentes e os espelhos. Convencionalmente, as imagens produzidas por esses dispositivos são divididas em duas categorias, aquela das chamadas imagens

\footnotetext{
${ }^{7}$ A presença das sombras entre as imagens poderia até ser julgada discutível, igualmente resolvemos acatar a inserção delas na tabela original de van Fraassen. É evidente que se trata de algo diferente de reflexos, fatas morganas, miragens e imagens 'produzidas por um microscópio' e portanto para elas não se aplica o discurso que faremos a seguir e que deveria permitir considerar as imagens de maneira geral (com exceção das sombras) como objetos. Contudo, as sombras também podem ser concebidas como entidades - pois podem facilmente ser descritas 'em termos dos objetos envolvidos' e portanto ser pensadas como eventos - e sem dúvida se trata de algo que vemos comumente. Mesmo que chegássemos à conclusão de que elas não são imagens propriamente ditas - a ponto de requerer um tratamento à parte, como aquele realizado por Roy Sorensen (cf. 2008) - e que, por isso, seria oportuno excluí-las da tabela, enfim, não poderíamos certamente deixar de considerá-las como fenômenos. Isso, todavia, não tornaria necessário falar nas 'alucinações públicas' como se essas constituíssem uma categoria ontológica à parte.
}

GAVA, Alessio. É possível ver imagens? (Ou do porquê van Fraassen deveria rever a sua abordagem em relação a elas). Griot : Revista de Filosofia, Amargosa-BA, v.18, n.2, p.143-160, dezembro, 2018. 
virtuais e aquela das chamadas imagens reais. Um clássico exemplo de imagem real é aquele da figura a seguir:

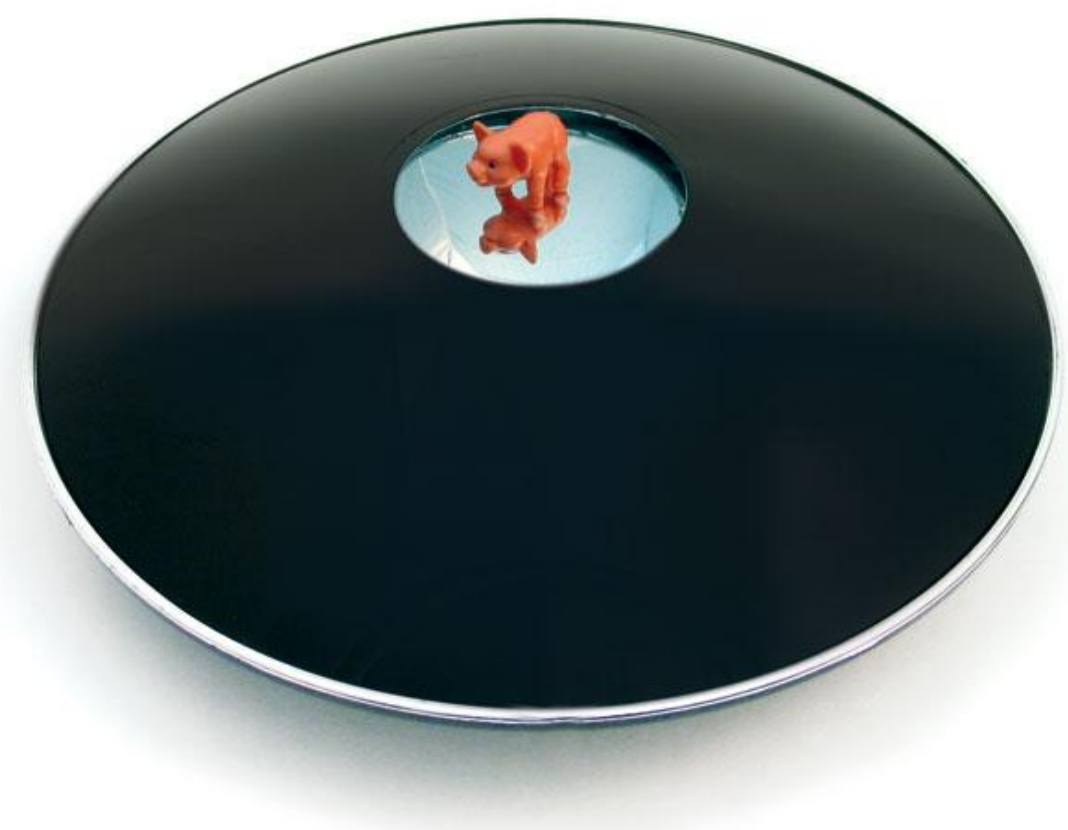

Figura 3 - Imagem de um brinquedo Mirage

Fonte <http:/www.teachersource.com/product/the-mirage/light-color $>$, último acesso em 16/06/2014

O dispositivo reproduzido na fotografia, muito popular, é chamado de Mirage, por ele produzir um efeito muito parecido com o fenômeno homônimo. No caso desse brinquedo, todavia, a impressão de que há um porquinho acima da abertura do recipiente escuro resulta da 'ação' de dois espelhos côncavos sobrepostos, e não, como pelo contrário acontece no deserto, pelo fato de as camadas de ar próximas do solo serem muito mais quentes do que aquelas superiores.

GAVA, Alessio. É possível ver imagens? (Ou do porquê van Fraassen deveria rever a sua abordagem em relação a elas). Griot : Revista de Filosofia, Amargosa-BA, v.18, n.2, p.143-160, dezembro, 2018. 


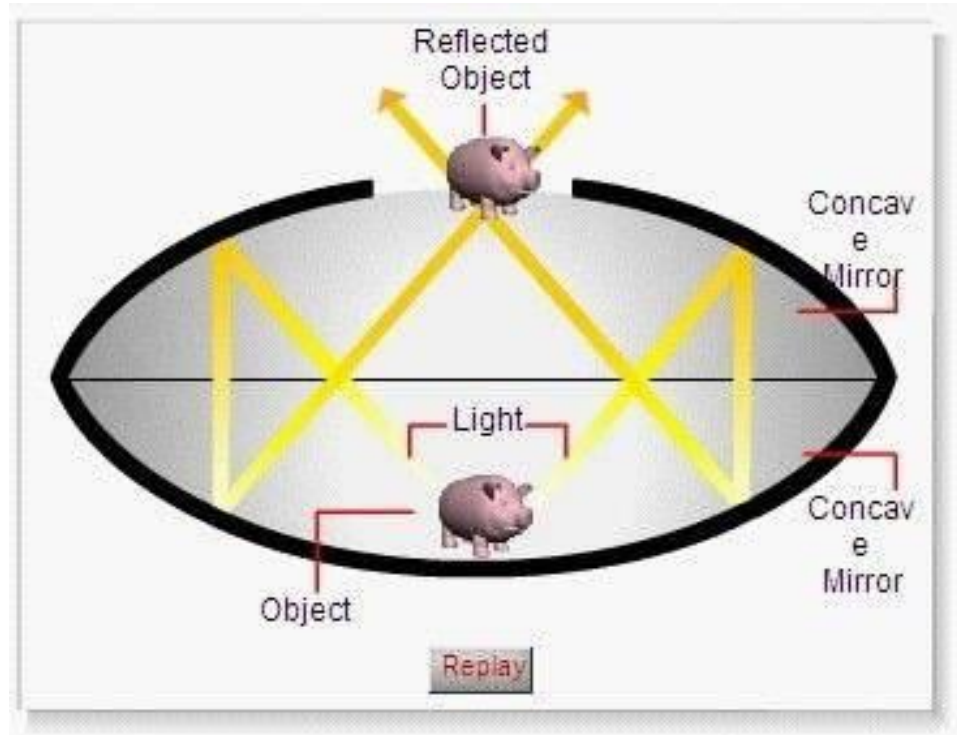

Figura 4 - Como funciona o brinquedo Mirage

Fonte <http://anajesusa.files.wordpress.com/2013/06/clip_image0061.jpg>, último acesso em 16/06/2014

No caso do Mirage, a luz que provém de um porquinho (de plástico) apoiado no fundo do recipiente se reflete nos espelhos côncavos que se encontram no interior e esses concentram os raios em uma região de espaço bem delimitada, acima da abertura. Dessa maneira, cria-se uma imagem do porquinho tão parecida com o 'objeto original' que se tem a impressão de que o porquinho esteja realmente apoiado na parte superior do 'vaso' e que seja possível tocá-lo ou até pegá-lo, quando de fato não há nada naquele lugar. Mas será que não há mesmo nada?

Essa imagem do porquinho é um exemplo de imagem real, assim dita pelo fato de ela corresponder a uma efetiva concentração de energia luminosa no ponto onde a imagem criou-se. Em um caso como esse, segundo explicam os livros de física, se colocarmos um anteparo no ponto onde os raios se concentram, a imagem resulta projetada como se nos encontrássemos em um cinema.

Ora, se uma imagem real corresponde a uma concentração de energia (luminosa) em uma região muito bem delimitada de espaço, não poderíamos então dizer que ali há uma entidade? Nosso pano de fundo teórico-conceitual geral é constituído pela teoria da relatividade de Einstein, como o próprio van Fraassen $\operatorname{diz}_{,}{ }^{8}$ e ela afirma a equivalência entre matéria e energia, atestada pela celebérrima equação $E=m c^{2}$. Poderíamos nos apoiar nessa para corroborar a opinião, expressa em Scientific Representation, de que uma imagem é algo, e não nada. Poderíamos até ir além e considerar que, se energia e massa representam 'os dois lados da mesma moeda', então é sim possível considerar uma imagem como uma entidade, pelo menos quando se trata de uma imagem real.

\footnotetext{
8 "[Van Fraassen] toma a teoria geral da relatividade - ou uma extensão dela - como o pano-de-fundo conceitual mediante o qual podemos pensar o problema dos limites gerais da observabilidade" (DUTRA 1993, p.142-143).
}

GAVA, Alessio. É possível ver imagens? (Ou do porquê van Fraassen deveria rever a sua abordagem em relação a elas). Griot : Revista de Filosofia, Amargosa-BA, v.18, n.2, p.143-160, dezembro, 2018. 
Para tanto, seria provavelmente necessário propor condições de identidade diferentes daquelas que permitem localizar e identificar um objeto material, ${ }^{9}$ como são aquelas que permitem reconhecer o porquinho de plástico que se encontra apoiado no fundo do recipiente do brinquedo Mirage, e no caso de uma imagem real pode não ser uma tarefa simples, mas parece igualmente tratar-se de algo realizável, pelo menos em princípio.

Dessa maneira, uma imagem real poderia ser legitimamente considerada observável por um empirista construtivo, que quisesse ater-se à afirmação de van Fraassen de que o termo observável faz referência a entidades, pois poderia, também, ser concebida como um objeto. ${ }^{10}$ A equivalência entre massa e energia, com efeito, permite pensar que um objeto pode apresentar-se tanto em forma 'material', dotado de massa, quanto em forma 'imaterial', como energia. A equação de Einstein torna possível, em princípio, a transformação de um objeto de uma forma para a outra e vice-versa. Um pouco como acontece com a mudança de fase de um corpo, que de sólido pode trasformar-se em líquido ou, em sentido inverso, de líquido pode trasformar-se em sólido - e não somente. Em rigor, aliás, em se tratando de uma identidade, a equação $E=m c^{2}$ deveria permitir até considerar que massa e energia são a mesma coisa e levar à conclusão de que não se deveria nem falar em algo análogo a uma mudança de fase.

Ora, há evidentemente diferenças entre um objeto concreto e uma 'imagem real'. Por exemplo: para um objeto material vale o princípio de impenetrabilidade, que não vale para uma imagem real; um objeto pode ser transportado, enquanto uma imagem não pode ser deslocada (pelo menos não da mesma maneira que o objeto, mas pode ser transportada ao deslocar o dispositivo que a produz); etc. Mas existem diferenças importantes também entre objetos que se encontram em fases diferentes: um sólido ocupa um volume próprio, já um líquido não; um líquido é incompressível, mas quando passa para o estado gasoso pode ser comprimido com facilidade; etc.

Uma imagem real, ademais, forma-se exteriormente ao olho do observador e é percebida como se fosse um objeto, do mesmo modo que no caso do porquinho do Mirage. Como a foto do brinquedo bem ilustra, nossos olhos não conseguem diferenciar a imagem real, formada pelos espelhos côncavos sobrepostos, de um objeto concreto. Em geral, sabemos que em um certo lugar existe um objeto porque a luz refletida e difundida por ele chega até nossos olhos e o cérebro interpreta essa informação. $O$ que o Mirage faz é criar uma imagem real acima do objeto (do qual ela é imagem), de maneira que os raios de luz que a formam chegam aos nossos olhos exatamente como quando se trata de feixes refletidos por um objeto material. Por isso, nosso cérebro interpreta essa informação como se no ponto imagem houvesse um objeto dotado de massa. Enfim, uma imagem real se comporta do mesmo modo que uma coisa e a teoria da relatividade nos diz que ela é, para todos os efeitos, equivalente a uma coisa. Por que não dizer,

\footnotetext{
${ }^{9}$ Isso foi sugerido pelo Prof. Otávio Bueno, da University of Miami, durante uma conversação pessoal.

10 Estamos aqui tentando uma estratégia que permita evitar falar em 'alucinações públicas' como se essas constituíssem uma categoria ontológica à parte.
}

GAVA, Alessio. É possível ver imagens? (Ou do porquê van Fraassen deveria rever a sua abordagem em relação a elas). Griot : Revista de Filosofia, Amargosa-BA, v.18, n.2, p.143-160, dezembro, 2018. 
então, que aquilo que é visto nesses casos é um objeto, ou que, pelo menos, tanto objetos quanto imagens reais são entidades? ${ }^{11}$

\section{As imagens virtuais}

Já com as imagens virtuais a situação é um pouco diferente. O próprio uso do adjetivo virtual parece indicar que se trata de algo que na verdade não existe. $O$ fato de ser habitual utilizarmos expressões como "ver o reflexo de Santa Maria Formosa nas águas do Rio del Mondo Novo’ não constitui uma garantia de que haja algo que pode ser considerado como uma imagem da igreja, na superfície do canal veneziano. Com efeito, não há nenhum ponto da trajetória dos raios onde, se posicionássemos um anteparo, se formaria uma imagem como quando projetamos um slide em um telão. Se trata de um caso diferente daquele das imagens reais, que, ao invés, correspondem a uma efetiva convergência e concentração de raios luminosos - e, consequentemente, de energia.

As imagens virtuais se formam sobre a retina, no globo ocular do observador, pela ação da lente do olho, que captura os raios (divergentes) aparentemente provenientes do ponto imagem e os faz convergir atrás do cristalino (a lente), de maneira a formar a imagem. É somente no interior do olho de quem observa, em outras palavras, que uma imagem virtual 'existe'. Sem o observador (ou um dispositivo de captura dos raios, como pode ser uma câmera fotográfica), não há imagem (virtual). Por isso, alguém poderia até afirmar que as imagens virtuais não existem e que dizer que vimos o reflexo de uma igreja em um canal de Veneza é uma resposta espontânea a algo que experienciamos, mas nada mais é, na verdade, do que uma façon de parler, que não corresponde àquilo que aconteceu de fato.

$\mathrm{O}$ argumento de van Fraassen contra imagens e arco-íris do artigo de 2001, isto é, parece poder ser aplicado às imagens virtuais. Mas o que é que vemos, então, ao olharmos para o espelho retrovisor do carro? O espelho? Uma imagem da ambulância que está atrás de nós? A própria ambulância? Se aquilo que queremos ver é o espelho, nossos olhos focam nele. Assim, o espelho torna-se nosso foco de atenção - até em um sentido 'físico': ele se encontra no ponto de convergência dos chamados raios visuais - e aquilo que é visto é o espelho. Se, diversamente, queremos ver a ambulância, mas sem ter que virar a cabeça enquanto estamos dirigindo, nossos raios visuais ‘atravessam' o retrovisor e se concentram em um ponto - o ponto imagem - que parece estar atrás do espelho. A figura a seguir mostra o que acontece:

11 Mutuando as palavras de van Fraassen, podemos dizer que o fato de ela ser imagem de algo, ao mesmo tempo que uma entidade, é importante mas irrelevante para esse ponto. Assim como é irrelevante saber que a estátua fotografada pelo ignaro turista representa o David da Bíblia, para classificá-la como objeto material - sem contar que se trata, no máximo, da imagem de alguma pessoa que posou como modelo para Michelangelo e não da imagem de ‘o maior rei de Israel'.

GAVA, Alessio. É possível ver imagens? (Ou do porquê van Fraassen deveria rever a sua abordagem em relação a elas). Griot : Revista de Filosofia, Amargosa-BA, v.18, n.2, p.143-160, dezembro, 2018. 


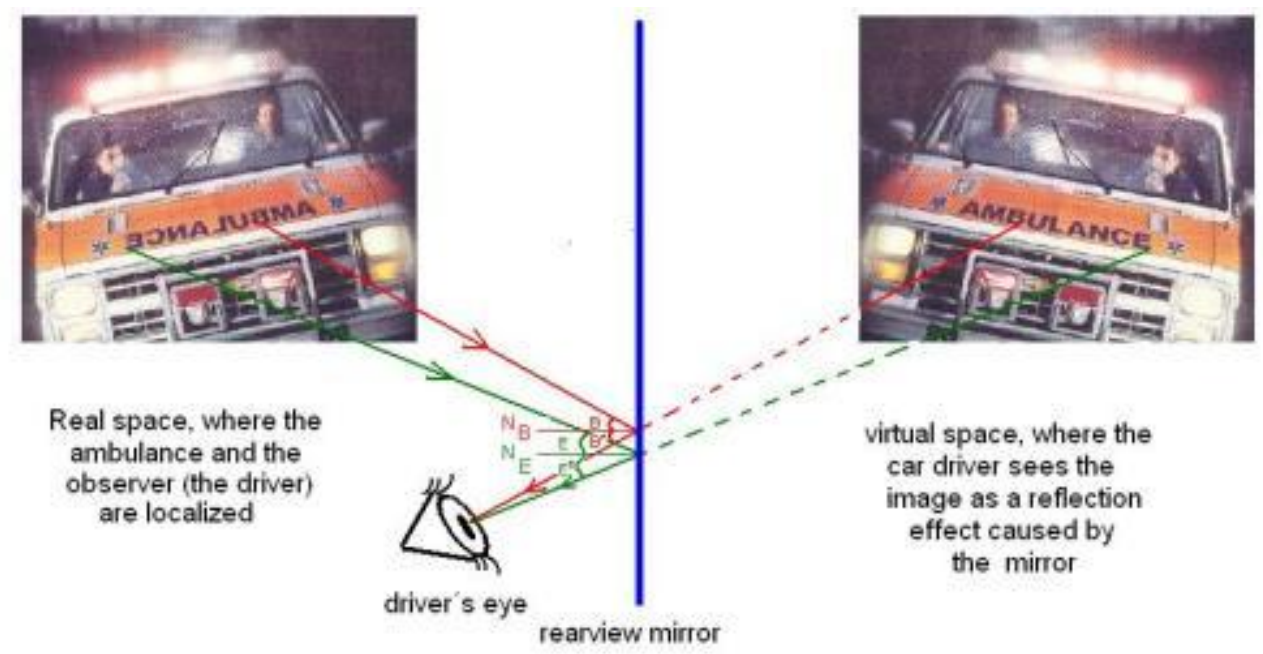

Figura 5 - Visão através do espelho retrovisor de um carro

Fonte <http://fisicafacil.wordpress.com/2009/02/25/ecnalubmaambulance-aicnalubmaambulancia >, último acesso em 02/04/2014

Aquilo que o observador do desenho recebe são feixes de luz que provêm da ambulância atrás dele, os quais, antes de chegar ao olho, refletem na superfície do espelho retrovisor (plano). A trajetória dos raios não é retílinea e por isso pode-se até dizer que a ambulância não foi observada diretamente. Igualmente, existem razões para afirmar que aquilo que foi visto nesse caso foi a ambulância e não o espelho ou uma imagem da ambulância. Essa última criou-se no interior do olho, não existe 'lá fora' ${ }^{12}$

Como pode ser notado pelo desenho, ademais, e como determinam as leis da reflexão, se dobrássemos a folha ao longo da linha do espelho plano, as 'duas ambulâncias' sobrepor-se-iam perfeitamente, assim como os raios que delas saem e vão até o espelho. É uma instância de simetria axial, no caso da qual normalmente se diz, justamente, que uma figura espelha a outra. A situação é análoga a quando aprendi a jogar basquete, muitos anos atrás. $O$ instrutor ensinou que existem duas maneiras de passar a bola para um colega: diretamente ou fazendo bater uma vez a bola no chão segundo uma trajetória simétrica, que, seguindo exatamente as leis da reflexão, dá lugar a um desenho muito parecido com aquele da página anterior. Em ambos os casos, aquilo que o colega recebe é a bola. O caminho dela não importa. Será que o mesmo pode ser dito da ambulância do desenho?

O fato de termos a impressão de que a ambulância está em outro lugar, em correspondência do ponto imagem, se deve ao fato de que, na grande maioria dos casos, recebemos a luz diretamente (retilinearmente) de um objeto e nosso cérebro processa

\footnotetext{
12 Para evitar dizer que, no processo de percepção da ambulância, um reflexo desempenhou algum papel, uma estratégia poderia ser aquela de dizer que a ambulância foi vista 'reflexivamente'. A possibilidade de usar o advérbio, no lugar do substantivo, poderia permitir pensar que a palavra reflexo nada mais é do que a reificação de algo que na verdade não existe. Algo parecido acontece em filosofia da percepão, na chamada teoria adverbial, que nega a existência dos dados sensorias atribuindo à própria experiência as qualidades percebidas e utilizando advérbios para descrevê-la.
}

GAVA, Alessio. É possível ver imagens? (Ou do porquê van Fraassen deveria rever a sua abordagem em relação a elas). Griot : Revista de Filosofia, Amargosa-BA, v.18, n.2, p.143-160, dezembro, 2018. 
automaticamente, entre outras coisas, informações sobre sua posição. A assunção de que os raios sempre chegam a nós por um caminho retilíneo é feita por default pelo cérebro, enganando-nos quanto à posição do objeto percebido quando o feixe de luz sofreu algum tipo de desvio. É o que acontece no caso de uma miragem ou de uma fata morgana, por exemplo. No caso de um espelho plano, isso pode até levar a situações cômicas como quando uma pessoa esbarra no espelho do saguão de um hotel acreditando ser aquela a saída. Mas o fato de a pessoa ter tido a impressão de que a saída encontrava-se do outro lado do saguão não significa que ela não a tivesse visto. A informação sobre a posição de um objeto é somente uma entre muitas que nosso cérebro processa ao observá-lo. Errar uma delas não significa não tê-lo observado. Assim como meu parcial daltonismo não me impede de ver o livro na minha frente, mas somente leva-me a ter uma impressão errada acerca da sua cor.

Em vista disso, como foi dito, pode parecer possível endossar a posição de van Fraassen de 2001 e negar a existência das imagens que a física classifica como 'virtuais'. Nessa perspectiva, poder-se-ia julgar que insistir que aquilo que foi visto nos exemplos fornecidos não foram a igreja na beira do canal e a ambulância e sim uma imagem delas, corroboraria, mesmo involuntariamente, a ideia de que, afinal, é sempre uma imagem aquilo que se vê quando a visão está envolvida. Isso porque a visão se dá por meio da formação, no interior do olho, de uma imagem que se cria sobre a retina e que é processada pelo cérebro. Assim, pode-se até pensar que aquilo que se vê é sempre uma imagem, mas isso não corresponde ao uso ordinário do verbo ver e não permitiria distinguir, por exemplo, entre um objeto e uma imagem, que são diferentes, mesmo admitindo que a diferença entre eles seja somente de forma e não de substância.

Portanto, se viro à minha esquerda e meu cérebro elabora a informação de que ali há um sofá marrom, porque um feixo de luz chegou retilinearmente até meus olhos, provindo desse objeto, e eu prestei atenção, posso sim dizer que vi o sofá e parece correto agir dessa maneira. A única imagem envolvida nesse processo é aquela que se criou sobre minha retina. Mas alguém poderia afirmar que exatamente a mesma coisa aconteceu quando vi Santa Maria Formosa reflexa no canal as sete da manhã no caminho para a biblioteca. A única imagem envolvida foi aquela que se criou na minha retina e que meu cérebro processou, informando-me, corretamente, de que há uma igreja na beira do Rio del Mondo Novo - não me forneceu a informação de que há uma igreja no canal e nem a informação de que estava vendo uma imagem. Logo, segundo essa linha de raciocínio, eu não vi uma imagem. E isso, como van Fraassen teria dito quinze anos atrás, nem poderia ter acontecido, porque imagens (virtuais) não existem e, por conseguinte, não podem ser vistas.

Dado por adquirido que a visão envolve sempre a formação de uma imagem fato que, dado nosso conhecimento do funcionamente do olho humano, ninguém coloca em discussão -, poderíamos então dizer que, sempre segundo essa linha de raciocínio, a diferença entre ver um objeto e 'ver' uma imagem depende, afinal, de onde se cria tal imagem: dentro ou fora do olho?

Um 'guia grosseiro' poderia ser o seguinte: se os raios provenientes do objeto convergem em um ponto exterior ao olho do sujeito percipiente, então a imagem que se

GAVA, Alessio. É possível ver imagens? (Ou do porquê van Fraassen deveria rever a sua abordagem em relação a elas). Griot : Revista de Filosofia, Amargosa-BA, v.18, n.2, p.143-160, dezembro, 2018. 
formou é real e deve ser considerada como um objeto - em outras palavras, é real de fato. Nesse caso, é correto dizer que vemos uma imagem, mas essa legitimidade decorre do fato de ela ser, para todos os efeitos, um objeto, que chamamos de imagem (como acontece, mutatis mutandis, com a estátua de David).

Se, ao invés, os raios provenientes do objeto somente convergem no interior do olho do sujeito percipiente, sobre a retina, então a 'imagem' é virtual. Para quem quisesse endossar a posição de van Fraassen de 2001, o adjetivo virtual deveria assim ser tomado em seu significado corriqueiro, como sinônimo de "parece que existe, mas na verdade não existe'. Não seria uma imagem, aquilo que foi visto, e sim o objeto de onde o feixe de luz proveio. Os raios, com efeito, sofreram um desvio em sua trajetória, mas eles próprios não foram alterados e carregaram a mesma informação que teriam carregado se não tivessem sido desviados ${ }^{13}$ - inclusive a informação sobre a posição do objeto; quem elaborou essa de maneira errada foi o cérebro. Exatamente como acontece no caso de uma miragem ou de uma fata morgana. Mas o que mais importaria é que os raios saíram do objeto e foram recombinados somente no interior do olho do sujeito percipiente, que é aquilo que acontece quando percebemos um objeto. Uma eventual mudança de trajetória, que poderia ser provocada pela presença de janelas, lentes, espelhos ou outros objetos ao longo do caminho, ou até mesmo pela diferença de densidade das várias camadas da atmosfera, não modificaria esse estado de coisas, a não ser que isso provocasse também a convergência do feixe exteriormente ao olho. Poder-seia dizer que não existe algo como uma 'imagem virtual', enfim. Logo, ela não pode ser vista.

Vale aqui dizer que a imagem que se forma sobre a retina, segundo o que acontece em qualquer instância de visão, é sempre real, como bem se sabe. Se levássemos esse fato em conta, porém, deveríamos então dizer que aquilo se vê é sempre uma imagem e não poderíamos mais dizer que vemos um objeto, quando olhamos para o livro que está em cima da mesa. Por outro lado, admitindo que as imagens virtuais não existem de fato - ideia que pode ser ulteriormente corroborada pelo fato de a imagem na retina ser sempre real - e que as imagens reais são na verdade objetos, a visão será sempre de objetos ou sempre de imagens, dependendo de como quisermos descrever o mesmo processo perceptivo (visual). Tratar-se-ia, simplesmente, das duas faces da mesma moeda. Entretanto, mais uma vez, vale a 'regra' de desconsiderar as experiências subjetivas, portanto quando se diz que Pablo e Salvador viram um exemplar de $A$

\footnotetext{
13 Osvaldo Pessoa, o qual considera que o objeto da percepção pode envolver qualquer etapa da cadeia causal que leva à percepção, diz que uma observação do Sol refletido no espelho pode ser considerada também uma observação do espelho, "mas uma observação de 'efeito nulo', ou seja, que modifica em nada ou muito pouco a situação sem a presença do espelho" (PESSOA 2011, p.375). Isso, explica Pessoa, se dá porque o espelho somente modifica a direção de propagação dos raios, mas não absorve e nem dispersa a luz. Segundo ele, a situação é a mesma de ver o Sol atrás de uma janela. A observação do astro pode ser considerada, também, uma observação do vidro, mas essa seria uma 'observação de efeito nulo'. "Trata-se de uma observação porque uma variação nas propriedades do vidro, por exemplo uma rachadura, seria observável", acrescenta Pessoa (2011, p.375). Pessoalmente discordo com a proposta 'causal-pluralista' do Prof. Pessoa, todavia aquilo que interessava aqui era expor os motivos, que poderiam ser compartilhados por quem quisesse negar a existência das imagens virtuais, que levam Pessoa a considerar que a 'observação' do espelho seria 'de efeito nulo'. Conquanto julgue que seria mais apropriado, nesse caso, dizer que ela (simplesmente) não ocorre.
}

GAVA, Alessio. É possível ver imagens? (Ou do porquê van Fraassen deveria rever a sua abordagem em relação a elas). Griot : Revista de Filosofia, Amargosa-BA, v.18, n.2, p.143-160, dezembro, 2018. 
Imagem Científica em cima da mesa, é correto considerar que ambos viram um objeto, situado exteriormente a eles, objetivamente e publicamente acessível. Em outras palavras, viram a mesma coisa. Pablo não viu a imagem real/objeto que está no interior do olho dele. Senão, Salvador teria visto uma coisa diferente, etc.

Van Fraassen, porém, alguns anos após ter afirmado que imagens não existem (sem operar nenhuma distinção entre imagens reais e virtuais) retratou e atualmente admite que nós de fato vemos imagens e que é acurado descrever dessa maneira a experiência que normalmente classificamos como 'ver uma imagem'. Isso parece correto e, apesar de term apresentado um possível argumento em favor de sua anterior negação de que imagens podem ser vistas, que deveria valer no caso das imagens virtuais, minha opinião é a mesma.

Com efeito, é verdade que sem um sujeito percipiente não há imagem (virtual), como foi dito anteriormente, e que essa 'segue' o observador em seus deslocamentos, analogamente ao caso do arco-íris. Por exemplo, o reflexo da igreja no canal está sempre situada em um plano imaginário que compreende também o edifício e o observador e, se esse ultimo se desloca, a imagem também 'desloca-se'. Todavia, esse reflexo também corresponde a uma concentração (mesmo que não a uma convergência) de energia luminosa e, por desempenhar um papel representacional, é classificado como imagem. $\mathrm{O}$ mesmo, aliás, acontece com qualquer 'imagem virtual' e por isso o argumento que nos levou a classificar as imagens reais como objetos pode ser estendido àquelas virtuais. No caso de essas últimas, os critérios de identificação deveriam provavelmente ser diferentes, posto que, por exemplo, as imagens reais não 'seguem' o observador e aquelas virtuais sim e que, sobretudo, a concentração de energia luminosa no caso das primeiras se deve a uma convergência de raios eletromagnéticos no chamado ponto focal (segundo afirmam 'nossas melhores teorias'), o que permite atribuir uma posição no espaço (independente do observador) à imagem real, enquanto com as imagens virtuais isso não é possível e a concentração de energia luminosa no caso dessas corresponde apenas a uma 'aglomeração' de raios divergentes. Todavia não há motivos pelos quais não deveria ser possível encontrar tais critérios, até no caso das imagens virtuais. ${ }^{14}$

\section{Conclusão}

O resultado de tudo isso pode ser resumido assim: van Fraassen tinha razão, nós não vemos imagens, somente vemos coisas. Imagens, com efeito, não existem (como categoria à parte). Isso porque aquelas que comumente são chamadas de imagens pela física são, na verdade, objetos. Só que a categoria das imagens que têm esse nome, mas

\footnotetext{
14 Para essas, aliás, existe certamente a possibilidade de atribuir uma posição no espaço, mesmo que relativa ao observador. Como disse justamente van Fraassen (cf. VAN FRAASSEN 2001, p.160), em casos como aquele do reflexo de uma igreja em um canal há determinadas relações geométricas invariantes entre o objeto, a imagem e o observador que tornam possível, conhecendo a localização do edifício e o 'ponto de observação', saber exatamente onde o sujeito verá a imagem da igreja. Nesse lugar, que se encontra na superfície do canal, há uma concentração de energia, mesmo que se trate de raios divergentes, o que permite dizer que ali há algo, assim como acontece no caso das imagens reais.
}

GAVA, Alessio. É possível ver imagens? (Ou do porquê van Fraassen deveria rever a sua abordagem em relação a elas). Griot : Revista de Filosofia, Amargosa-BA, v.18, n.2, p.143-160, dezembro, 2018. 
que na verdade são objetos, é mais ampla do que van Fraassen pensa(va) e inclui todas aquelas que em física são chamadas de imagens (tanto reais quanto virtuais).

A classe dos objetos que podem ser observados, não contém somente coisas concretas, mas vai além daquilo que o 'realismo do senso comum' sugere. Além de pedras, oceanos, bicicletas, podemos ver também o porquinho 'imaterial' do Mirage e os arco-íris (e a própria luz?). Contudo, os objetos da percepção são efetivamente entidades (objetos, eventos, processos), assim como van Fraassen sempre sustentou. Até no caso das imagens.

GAVA, Alessio. É possível ver imagens? (Ou do porquê van Fraassen deveria rever a sua abordagem em relação a elas). Griot : Revista de Filosofia, Amargosa - BA, v.18, n.2, p.143-160, dezembro, 2018. 


\section{Referências}

DE ARAÚJO DUTRA, Luiz Henrique. Van Fraassen e os limites da observabilidade. Cadernos de História e Filosofia da Ciência, Campinas, Série 3, n. 3 (1/2), p. 133-150, jan.-dez. 1993.

FRAASSEN, B. C. van. Constructive Empiricism now. Philosophical Studies, s.l., n. 106 (1-2), p. 151-170, 2001. 2008.

. Scientific Representation: Paradoxes of Perspective. Oxford: Clarendon Press,

GAVA, Alessio. Somewhere over the... what?. Filosofia Unisinos - Unisinos Journal of Philosophy, São Leopoldo, RS (Brazil), v. 17, n. 3, p. 315-319, set./dez. 2016.

GIERE, Roland N. Essay Review: Scientific Representation and Empiricist Structuralism. Philosophy of Science, s.l., v. 76, n. 1, p. 101-111, jan. 2009.

LATHAM, William. Account of a Singular Instance of Atmospherical Refraction. In a Letter from William Latham, Esq. F. R. S. and A. S. to the Rev. Henry Whitfeld, D. D. F. R. S. and A. S. Philosophical Transactions of the Royal Society of London, Londres, v. 88, p. 357-360, 1798.

PESSOA JÚNIOR, O. Uma teoria causal-pluralista da observação. In: Mortari, C.A. \& Dutra, L.H.A.. (Org.). Anais do VII Simpósio Internacional Principia. 1 ed. Florianópolis: Núcleo de Epistemologia e Lógica - UFSC, 2011, v. 11, p. 368-381. SORENSEN, Roy. Seeing Dark Things: The Philosophy of Shadows. Oxford: Oxford University Press, 2008.

Autor(a) para correspondência: Alessio Gava, Universidade Estadual do Paraná, Rua Pernambuco, 858, Centro, CEP 87701-010, Paranavaí - PR, Brasil. alessiogava@yahoo.it

GAVA, Alessio. É possível ver imagens? (Ou do porquê van Fraassen deveria rever a sua abordagem em relação a elas). Griot : Revista de Filosofia, Amargosa-BA, v.18, n.2, p.143-160, dezembro, 2018. 